\title{
Achieving Health Equity in Urban Settings
}

Tord Kjellstrom, Susan Mercado, Mojgan Sami, Kristin Havemann, and Soichiro Iwao

\section{HEALTH EQUITY AND THE INTERNATIONAL COMMUNITY}

This issue of the journal is devoted to the social determinants of health in urban settings and associated interventions that protect health and promote health equity. The great disparity in health opportunities and health status between and within different population groups in and between countries at different economic development levels is one of the great challenges for the global community at the beginning of the 21st century. ${ }^{1}$ The international community debated the issues of poverty, economic development, and health at a number of major summits toward the end of the 20th century, including the Rio Earth Summit in $1992^{2}$ and the Copenhagen Social Summit in 1995. However, without specific targets or agreed dates for achieving those targets, progress on social and health equity was insufficient. One major reason was the lack of financial resources because of the noncompliance of affluent countries with the agreed aid target of $0.7 \%$ of their $\mathrm{GDP}^{3}$

At the turn of the century, the international community took up the challenge of achieving better equity by formulating the Millennium Development Goals at the Millennium Summit in $2000,{ }^{4}$ many of which include priority health issues. Progress is visible for some of the goals, but not enough for them to be met by the target year: 2015. ${ }^{5}$ The targets address the needs of the poorest people, but economic and social inequities and associated health inequities remain. ${ }^{6}$ It should also be remembered that the Universal Declaration on Human Rights, which almost all countries have signed, expressly states that all people have a right to live in conditions that promote health and protect life.

\section{THE INITIATIVE OF THE WORLD HEALTH ORGANIZATION}

The World Health Organization (WHO) has, since its establishment, actively advocated policies to improve the health of the poor. An intensified approach was flagged when the former Director General, Dr. J.W. Lee, launched the WHO Commission on Social Determinants of Health (CSDH) in March 2005. Its aim was to advance a health equity agenda and strengthen the organization's support to

Kjellstrom is with the National Institute of Public Health, Ostersund, Sweden; Kjellstrom is with the National Centre for Epidemiology and Population Health, Australian National University, Canberra, Australia; Kjellstrom is with the Health and Environment International Trust, Mapua, Nelson, New Zealand; Mercado, Sami, Havemann, and Iwao are with the WHO Kobe Centre for Health Development, Kobe, Japan.

Correspondence: Tord Kjellstrom, Health and Environment International Trust, Mapua, Nelson, New Zealand. (E-mail: kjellstromt@yahoo.com) 
Member States in implementing comprehensive approaches to health problems, including their social and environmental roots. The work of the commission is supported by nine knowledge networks that focus on the social determinantsrelated themes of early childhood development, health systems, measurement and evidence, employment conditions, globalization, women and gender equity, social exclusion, priority public health problems, and urban settings. The main focus of the knowledge networks is on synthesizing knowledge to inform the commission of opportunities for improved action on social determinants of health.

In this regard, the WHO Centre for Health Development in Kobe, Japan (WKC) was selected as the hub of the Knowledge Network on Urban Settings (KNUS). The center is an integral part of the secretariat of the WHO and was established in 1995 under a memorandum of understanding with the Kobe Group. * The center was directed to concentrate on issues related to health development, with particular emphasis on health care delivery and urbanization, delineating the place of health systems in society, and determining links between population, the economy, and the environment, and assessing health needs from a development perspective. In June 2005, the memorandum of understanding between WHO and the Kobe group was extended for another 10 years. The program of work was reviewed and it was agreed that work would be more sharply focused on urbanization as a cross-cutting driving force in health development.

The core membership of KNUS consists of a dozen international experts, each from a different geographic region. This group constituted the "Core Circle" of KNUS. At the first meeting in February 2006, the group reviewed a detailed report on health challenges for the poor ${ }^{7}$ and identified 60 topics and issues that were relevant to the synthesis of global knowledge and evidence on social determinants of health in the urban setting.

Based on those topics and issues, members of KNUS and additional writers were then commissioned to generate thematic papers on selected key themes. This was supplemented by stakeholders at the local level who were able to articulate some of the "voices from the urban settings," as well as perspectives from local journalists who compiled "vignettes" from life in informal settlements. In addition, representative case studies were prepared from the thematic papers to further delineate "best practices." The thematic papers and some of the "voices from the urban settings" were presented at a second meeting of KNUS at Dar es Salaam, United Republic of Tanzania in November 2006. The meeting included practitioners, policymakers, community-based organizations, researchers, and WHO Regional Focal Points. More than fifty individuals participated in the second meeting, the "Synergy Circle," whose main task was to review, discuss, and critique the thematic papers, provide additional inputs, and identify opportunities for scaling up. The group was also asked to reflect on potential "key messages" for the report to the CSDH. ${ }^{8}$

\footnotetext{
"The Kobe group refers to the local funding partners of the WKC, comprised of Hyogo Prefecture, Kobe City, the Kobe Chamber of Commerce and Industry, and Kobe Steel, Ltd. The Kobe Group contributes all operating funds for WKC.
} 


\section{THE THEMATIC PAPERS PUBLISHED IN THIS ISSUE OF THE JOURNAL}

The resulting 15 thematic papers have been abridged for inclusion in this issue. Selected vignettes and case studies identified for further analysis by the WHO Kobe Centre can be accessed online at http://www.who.or.jp/. Whereas the KNUS analysis is still in progress, final conclusions and recommendations have yet to be articulated. With the addition of an introductory editorial from the WHO Kobe Centre, this issue presents the following abridged thematic papers under six themes:

- Urbanization as a key factor in health equity development: Current economic development models contribute to the proliferation of informal settlements and intolerable living conditions for millions of people. In this section, a conceptual framework for organizing determinants of health in the urban setting is presented. ${ }^{9}$ It is argued that the complexity of cities requires a similar level of complex intervention, which is one of the many features of intersectoral approaches. Social determinants of health in the urban setting are reviewed, and methodological tools and challenges are considered. ${ }^{10}$ Finally, the links between globalization, economic growth, urbanization, and the formation of informal settlements are discussed. $^{11}$

- Reducing the burden of disease, disability and death in the urban setting requires attending to the social determinants of health. Emerging risks to the current burden of disease are reviewed in relation to urban populations. ${ }^{12}$ Exclusion from health statistics and inability to access services are highlighted as key challenges to the control of HIV-AIDS, tuberculosis, and vector-borne diseases in poor urban populations. ${ }^{13}$ The links between urban sprawl and noncommunicable disease are presented. Road accident injuries, obesity, urban violence, and unsafe settlements that are prone to hazards such as fires are highlighted as emerging threats to health in cities. The role of primary health care in the urban setting and the relevance of the healthy settings approach is revisited, ${ }^{14}$ and a case study on urban disasters in Indonesia is included. ${ }^{15}$

- The urban living environment can threaten or support human health and it is determined by social factors. This section presents the links between the social and environmental determinants of health in the urban setting. Interventions to improve health equity through the environment are noted dealing with drinking water, sanitation, solid waste removal, wastewater drains, air pollution, traffic injury hazards, work environments, and heat stress because of climate change. The adverse impact of global warming on the urban poor and the implications for environmental health and equity are recognized. ${ }^{16,17}$ In a report covering urban food and nutrition systems and unequal access to available dietary diversity, calories, and gastronomically satisfying eating experiences, it is argued that understanding the determinants of inequalities in food security and nutritional quality is a prerequisite for preventive policy responses for better nutrition in the urban setting. ${ }^{18}$ Best practices for meeting the housing and shelter needs of the urban poor are revisited. Issues, challenges, and opportunities for scaling up are considered. ${ }^{19}$

- Building trust, social capital, and social cohesion via participatory and empowering processes is critical to creating fairer health opportunities. Emphasis in this section is on the importance of social processes (participation, social capital, social accountability, and social inclusion) to approaches that address social determinants of health. Social capital is highlighted as a key factor influencing 
health outcomes and technical interventions in the urban setting. Ten key elements for building social capital are presented as an option for action. ${ }^{20,21}$

- Healthy urban governance, health services, and integrated approaches to interventions are key pathways to reducing health inequity. Here, it is argued that urban health depends on governance. The systems, institutions, and processes that promote better and fairer distribution of health in urban settings are a key and critical pathway for reducing health inequity in cities. ${ }^{22}$ The role of meaningful participation, empowerment, and participatory governance in reducing health inequity is highlighted. ${ }^{23}$

\section{TOWARD SUSTAINED ACTION TO ACHIEVE HEALTH EQUITY IN URBAN SETTINGS}

The WKC views partnership with the Journal of Urban Health through this supplement as a key means of sustaining momentum for action and research on social determinants of health in urban settings. Consistent with the center's framework of "health in development," the articles of this supplement contribute to the growing body of scientific knowledge and evidence on development models that protect health as a human right, achieve social justice, and ensure fairer health opportunities for all in our cities.

The work that is presented here reflects the outputs of the first year of KNUS that contribute to the development of the network's final report to the CSDH. That report will provide a synthesis of global knowledge and evidence, an analysis of interactions and pathways, and recommendations for scaling up effective interventions. In the future, WKC will disseminate the work of KNUS through "Breakthrough Circles" composed of cities, communities, and local partners who can take action and utilize a social determinants approach to health in the urban setting.

WKC extends its thanks to all the contributors and reviewers who were involved in the preparation of this supplement. This work would not have been possible without strong support from the WHO Regional Focal Points on social determinants of health in the urban setting: Chris Mwikisa and Hawa Senkoro (African Regional Office), Marilyn Rice (American Regional Office/Pan-American Health Organization), Sameen Siddiqi (Eastern Mediterranean Regional Office), Erio Ziglio (European Regional Office), Davison Munodawafa (South-East Asian Regional Office), Anjana Bhushan and Hisashi Ogawa (Western Pacific Regional Office). Special thanks are due to Sarah Simpson (CSDH Secretariat). The center would also like to acknowledge the work of Roy Wadia, Andrew Kiyu, Steve Tamplin, and Wilfred Kreisel in the conceptualization of the KNUS.

Urban settings are complex and diverse. The work of KNUS attempts to capture strategic information and evidence amid this complexity. The inextricable link between social, environmental, cultural, and political determinants and drivers of health in cities is an underlying theme of many of these papers. The importance of context in crafting policy responses is another.

It is clear that the linkages and pathways to fairer health opportunities must be navigated through complex social and political processes at multiple levels, involving multiple actors. This complexity necessitates innovative mechanisms for 
financing and implementing interventions that may need to be linked across cities, sectors, and societies. Healthy urban governance has been described as a critical pathway for managing these driving forces, securing the financial and human resources needed to navigate the process of change, and expanding the policy space for more balanced urban development.

As Amartya Sen has proposed,

Development can be seen...as a process of expanding the real freedoms that people enjoy. Focusing on human freedoms [or capabilities] contrasts with the narrower views of development, such as identifying development with the growth of gross national product, or with the rise in personal incomes, or with industrialization, or with technological advance, or with social modernization. ${ }^{24}$

Achieving health equity in the urban setting requires action toward fairness and equity within and between countries. Engaging the people themselves, urban communities, and multiple sectors in the urban development process is a must.

\section{REFERENCES}

1. Marmot M. Health in an unequal world. Lancet. 2007;368:2081-2094.

2. UN. Agenda 21. New York: UN; 1992.

3. Sachs J. The End of Poverty: How We Can Make it Happen in our Lifetime? London: Penguin Books; 2005.

4. UN. The Millennium Development Goals Report. New York: United Nations; 2005.

5. UNDP. Human Development Report: Beyond Scarcity: Power, Poverty and the Global Water Crisis. New York: United Nations Development Programme; 2006.

6. Kawachi I, Wamala SP. Poverty and inequalities in a globalized world. In: Kawachi I, Wamala SP, eds. Globalization and Health. New York: Oxford University Press; 2007:122-137.

7. WKC. A Billion Voices. Kobe: WHO; 2006.

8. WKC. Report of the 2nd Meeting of the Knowledge Network of Urban Settings. Kobe: WHO; 1-4 Nov 2006.

9. Vlahov D, Freudenberg N, Proietti F, et al. Urban as a determinant of Health. J Urban Health. 2007: DOI 10.1007/s11524-007-9169-3.

10. Ompad D, Galea S, Caiaffa W, Vlahov D. Social determinants of the health of urban populations: Implications for intervention. J Urban Health. 2007 (in press).

11. Yusuf S, Nabeshima K, Ha W. Income and health in cities: the messages from stylized facts. J Urban Health. 2007: DOI 10.1007/s11524.007.9186-2.

12. Campbell T, Campbell A. Emerging disease burdens and the poor in cities of the developing world. J Urban Health. 2007: DOI 10.1007/s11524-007-9181-7.

13. David A, Becker D, Edmundo K, Mercado S, Mugisha F. The prevention and control of HIV/AIDS, TB and vector-borne diseases in slums and informal settlements: challenges, opportunities and insights. J Urban Health. 2007: DOI 10.1007/s11524-007-9183-5.

14. Lee A, Kiyu A, Molina H, Jimenez de la Jara J. Improving health and building human capital through effective primary care system and healthy setting approach. J Urban Health. 2007 (in press).

15. Leitmann J. Cities and calamities: learning from post-disaster response in Indonesia. J Urban Health. 2007: DOI 10.1007/s11524-007-9182-6.

16. Kjellstrom T, Friel S, Dixon J, et al. Urban environmental health hazards and health equity. J Urban Health. 2007: DOI 10.1007/s11524-007-9171-9. 
17. Campbell-Lendrum D, Corvalan C. Climate change and health in developing country cities. J Urban Health. 2007: DOI 10.1007/s11524-007-9170-x.

18. Dixon J, Friel S, Omwega A, Donati K, Burns C, Carlisle R. The health equity dimensions of urban food systems. J Urban Health. 2007: DOI 10.1007/s11524-0079176-4.

19. Sheuya S, Patel S, Howden-Chapman P. Improving health and building human capital through an effective primary care system and healthy setting approach. J Urban Health. 2007 (in press).

20. Ooi GL, Phua KH. Urbanization and slum formation. J Urban Health. 2007: DOI 10.1007/s11524-007-9167-5.

21. Pridmore P, Havemann K, Sapag J, Thomas L, Wood L. Social Capital and Healthy Urbanization in a Globalized World. J Urban Health. 2007: DOI 10.1007/s11524-0079172-8.

22. Burris S, Hancock T, Herzog A, Lin V. Emerging strategies for healthy urban governance. J Urban Health. 2007: DOI 10.1007/s11524-007-9174-6.

23. Barten F, Hardoy A, Mitlin D, Mulhollan C, Stern R. Integrated approaches to address the social determinants of health for reducing health inequity. J Urban Health. 2007: DOI 10.1007/s11524-007-9173-7.

24. Sen A. The capability approach. Available at: http://www.fas.harvard.edu/ freedoms/. Accessed on: 14 Feb 2007. 